\title{
Cerimônias de homenagens ao "fundador da República brasileira" realizadas na Escola Agrotécnica Federal de São Cristóvão - SE (1939-1960)
}

\begin{abstract}
Resumo
Este artigo investiga a apropriação da imagem de Benjamin Constant pela EAFSC-SE, através da compreensão das cerimônias cívicas anuais de que foi destinatário como patrono da Instituição. Foram consultadas fontes documentais diversas e entrevistas. Na Escola, as cerimônias de homenagens a Benjamin Constant tiveram origem quando, em 1939, o "fundador da República" foi erigido a patrono do Estabelecimento. Nos anos que se seguiram, a Instituição tratou de incutir nos alunos a admiração, o respeito e a saudação a Benjamin Constant. Nas cerimônias institucionais em homenagem ao patrono, além do desfile cívico, ocorriam cantos cívicos, hasteamento da bandeira nacional, discursos, palestras, o almoço de confraternização e atividades esportivas. A apropriação da imagem deste vulto nacional servia para incutir o civismo e o patriotismo entre os alunos.
\end{abstract}

Joaquim Tavares da Conceição

Universidade Federal de Sergipe UFSE - SE/Brasil joaquimcodapufs@gmail.com

Palavras-chave: Benjamin Constant; Ensino Agrícola; Escola Agrotécnica Federal de São Cristóvão; Sergipe.

\section{Para citar este artigo:}

CONCEIÇÃO, Joaquim Tavares da. Cerimônias de homenagens ao "fundador da República brasileira" realizadas na Escola Agrotécnica Federal de São Cristóvão - SE (1939-1960). Revista Linhas. Florianópolis, v. 17, n. 34, p. 225-241, maio/ago. 2016.

DOI: $10.5965 / 1984723817342016225$

http://dx.doi.org/10.5965/1984723817342016225 


\title{
Ceremonies of tributes to the "founder of Brazilian Republic" on the Agro Technical Federal School from São Cristovão - SE (1939-1960)
}

\begin{abstract}
This article investigates the appropriation of Benjamin Constant's image from EAFSC-SE, through the comprehension of the annual civic ceremonies of which he was the addressee as patron of the institution. Several documental sources and interviews were consulted. In school, the ceremonies of tributes to Benjamin Constant had origin when, in 1939, the "republic founder" was risen to the establishment's patron. On the following years, the institution tried to instill in students the admiration, respect and greeting to Benjamin Constant. In institutional ceremonies in honor of the patron, besides the civic parade, it occurred civic chants, raising of the national flag, speeches, lectures, confraternization lunch, and sports activities. The image appropriation of this national figure served to instill civility and patriotism among students.
\end{abstract}

Keywords: Benjamin Constant; Agricultural Education; Agro Technical Federal School from São Cristovão; Sergipe. 


\section{Benjamin Constant: o "fundador da República brasileira"}

Benjamin Constant Botelho de Magalhães nasceu no dia 18 de outubro de 1836, na cidade de Niterói. Formado em Engenharia Civil e Militar pela Escola Militar, passou a lecionar Matemática em diversas escolas civis e militares do Rio de Janeiro, a exemplo da Escola Militar, Escola Politécnica, Escola Superior de Guerra e no Imperial Instituto dos Meninos Cegos. Era adepto e divulgador da doutrina positivista e foi um dos articuladores do "golpe militar" de 15 de novembro de 1889, que resultou na Proclamação da República (CASTRO, LEMOS, 2009; MENDES, 1936).

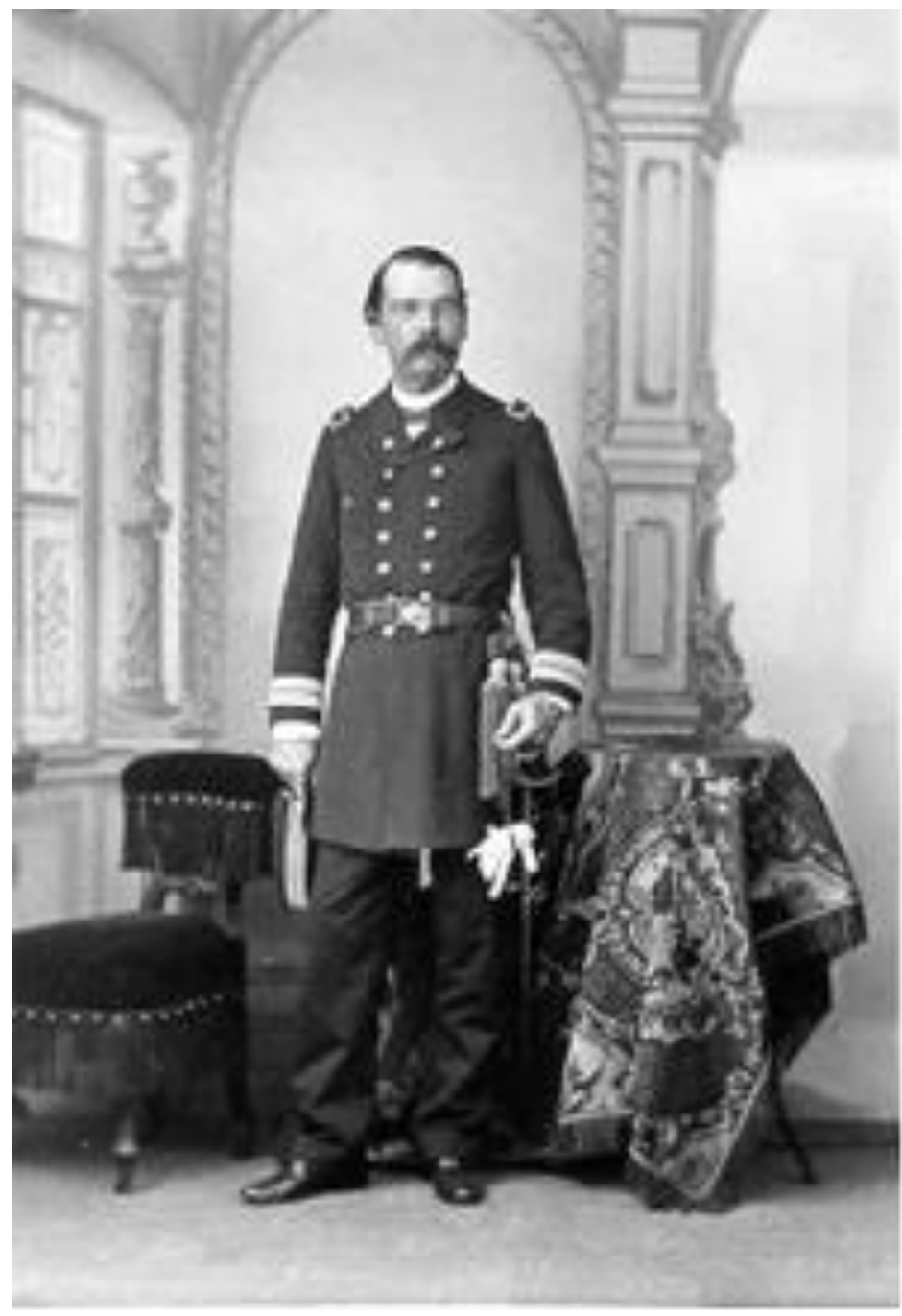

Figura 1: Retrato de Benjamin Constant Botelho de Magalhães. Acervo do Instituto Benjamin Constant. 
Com o sucesso do movimento republicano, Benjamin Constant passou a ter grande influência e prestígio político no Governo Provisóvio do Marechal Deodoro da Fonseca (1889-1891). Foi nomeado sucessivamente titular das pastas do Ministério da Guerra e do Ministério da Instrução Pública, Correios e Telégrafos (CASTRO, LEMOS, 2009; LEMOS, 1997). Benjamin Constant faleceu no dia 22 de janeiro de 1891, na cidade do Rio de Janeiro (MENDES, 1936). Alguns dias depois, precisamente em 24 de fevereiro de 1891, a primeira Constituição Republicana é promulgada, na qual os deputados constituintes prestaram-lhe a homenagem póstuma de "fundador da República", constando nas disposições transitórias do texto constitucional que:

Art. $8^{\circ}$ - O Governo federal adquirirá para a Nação a casa em que faleceu o Doutor Benjamin Constant Botelho de Magalhães e nela mandará colocar uma lápide em homenagem à memória do grande patriota - o fundador da República.

Parágrafo Único - A viúva do Dr. Benjamin Constant terá, enquanto viver, o usufruto da casa mencionada. (BRASIL, 1891)

Em comemoração ao seu centenário de nascimento ocorrido em 18 de outubro de 1936, entre outras homenagens oficiais, a data natalícia foi declarada feriado nacional, com a determinação de que fosse realizada uma sessão cívica alusiva àquela data, em todos os estabelecimentos do país (BRASIL, 1936). Assim, no decorrer da República, a imagem pessoal construída por Benjamin Constant,

[...] orientada por rigoroso modelo de virtude - ética, principalmente -, forneceu preciosos elementos ao processo de elaboração simbólica da explicação da República. [...] A apropriação de que sua imagem foi objeto constituiu uma rica manifestação da visão de mundo dos republicanos, uma tomada de posição em favor de valores com ele identificados. Isso ganhou forma na torrente de manifestações que se seguiram à sua morte, como batismo de crianças, unidades militares e clubes republicanos com seu nome e, em 1893, a formação do 'Batalhão Patriótico Benjamin Constant', que combateu a Revolta da Armada em Niterói. (LEMOS, 1997) 


\section{Benjamin Constant: Erigido a patrono da escola}

A Escola Agrotécnica Federal de São Cristóvão está situada no povoado Quissamã, município de São Cristóvão, estado de Sergipe. Atualmente, é parte integrante do Instituto Federal de Sergipe (IFS), com a denominação de Campus São Cristóvão. A origem da instituição ocorreu no ano de 1924 quando surgiu o Patronato Agrícola São Maurício, instituição assistencial dedicada à regeneração de menores desvalidos e formação de mão de obra agrícola, fundado pelo então Presidente do Estado, Maurício Graccho Cardoso (NERY, 2006). No ano de 1934, com a federalização do Patronato, foi implantado em seu lugar o Aprendizado Agrícola de Sergipe. No período que compreende o recorte temporal deste artigo (1934-1967), a instituição esteve vinculada ao Ministério da Agricultura e, nesse espaço de tempo, funcionou e desenvolveu diversos modelos de ensino agrícola: Aprendizado Agrícola (1934-1947), Escola de Iniciação Agrícola (1946-1952), Escola Agrícola (1952-1957), Escola Agrotécnica (1957-1964) e Colégio Agrícola (1964-1979) (CONCEIÇÃO, 2012; NASCIMENTO, 2004). No ano de 1967, ocorreu a transferência do ensino agrícola e de toda a rede federal dos estabelecimentos desse ramo de ensino do Ministério da Agricultura para a competência do Ministério da Educação (BRASIL, 1967) e, a partir de 1979, a instituição recebeu a denominação de Escola Agrotécnica Federal de São Cristóvão (EAFSC-SE).

A apropriação da imagem de Benjamin Constant pela EAFSC-SE teve como origem o dia 6 de janeiro de 1939. Nesta data, para homenagear o "fundador da República", o Aprendizado Agrícola de Sergipe (1934-1938) passou a ser denominado Aprendizado Agrícola Benjamin Constant (BRASIL, 1939). O diretor José Augusto de Lima, informado da mudança através de ofício do Superintendente do Ensino Agrícola, tratou de oficiar a mudança às autoridades estaduais, repartições federais e estaduais, imprensa, empresas particulares, entre outras, a exemplo do ofício encaminhado ao Interventor do Estado:

Ao Interventor Federal do Estado de Sergipe

$\mathrm{Exm}^{\circ} \mathrm{Sr}$. Dr. Interventor Federal, deste Estado.

De acordo com o ofício $n^{\circ} 38$, de 10 deste mês, da Superintendência do Ensino Agrícola, Ministério da Agricultura, comunico a V. Ex. para os devidos fins, que por Decreto-lei $n^{\circ} 1029$, de 6 do mês vigente, esta instituição passou a denominar-se Aprendizado Agrícola Benjamin Constant. 
Reitero a V. Ex. os meus protestos de alta consideração e respeitosos apreço

José Augusto de Lima - Diretor. (APRENDIZADO AGRÍCOLA BENJAMIN CONSTANT, 1939)

A mudança na denominação do Aprendizado Agrícola foi mais um ato do Governo Getúlio Vargas, por iniciativa do Ministro da Educação, Gustavo Capanema, para homenagear o centenário de nascimento de Benjamin Constant e, através do "culto" a esse vulto nacional, despertar o civismo na educação da mocidade brasileira. Nos anos que se seguiram, a "equipe dirigente" tratou de dar efetividade ao ato legal, incutindo nos internos a admiração, o engrandecimento, o respeito e a saudação ao "fundador da República".

No ano de 1939, por ocasião da cerimônia comemorativa do cinquentenário da Proclamação da República, o quadro de Benjamin Constant foi solenemente inaugurado no "salão de honra" do estabelecimento (APRENDIZADO AGRíCOLA BENJAMIN CONSTANT, 1939, p. 1) e, no final da década de 1960, um grande quadro de Benjamin Constant ficava no hall do edifício-internato (SANTOS, 2006). Precisamente durante os anos de 1942 a 1944, a homenagem ao patrono ensejou a formação do "grupo de escoteiro Benjamin Constant". O escotismo foi introduzido e coordenado na instituição pelo ex-oficial militar e auxiliar-agrônomo Achylles Peret (CONCEIÇÃO, 2012). Duas vezes por semana, os internos recebiam instruções de escotismo e no dia "18 de outubro" eles se apresentavam devidamente fardados, com o traje de escoteiro em homenagem ao patrono Benjamin Constant (APRENDIZADO AGRíCOLA BENJAMIN CONSTANT, 1942). Com toda a potencialidade que o espaço rural do Aprendizado oferecia (animais, rios, matas), além de incutir padrões de civismo e moralidade, o escotismo foi apropriado pelos internos como uma atividade recreativa. 


\section{Incutindo princípios de moralidade, civilidade e patriotismo}

$\mathrm{Na}$ cultura do internato da EAFSC-SE, houve lugar para um conjunto de práticas institucionalizadas ou "cerimônias institucionais", marcadas pela periodicidade, participação coletiva (internos, “equipe dirigente”, visitantes) e com finalidades diversas. Por "cerimônias institucionais" entende-se

[...] um conjunto de práticas institucionalizadas - seja espontaneamente, seja por imitação - através das quais os internos e a equipe dirigente chegam a ficar suficientemente perto para ter uma imagem um pouco mais favorável do outro e a identificar-se com a situação do outro. Tais práticas exprimem solidariedade, unidade e compromisso conjunto com relação à instituição, e não diferenças entre os dois níveis. (GOFFMAN, 1974, p. 85)

Foram comuns, na cultura da instituição, as cerimônias de comemorações cívicas, “A maior festa era no dia do patrono da escola" (LIMA, 2005). As cerimônias institucionais quase sempre tiveram como finalidade a inculcação dos valores institucionais, a interligação entre os internos e a "equipe dirigente" e a manutenção das relações com o macrocosmo social (exibição institucional). Também procuravam garantir o equilíbrio do microcosmo social, evitando os atos contrários às normas institucionais (os desvios) ao mesmo tempo em que suavizavam os rigores do internamento.

Os valores que a instituição procurou incutir, ou com os quais ela procurou apresentar-se nas cerimônias, foram principalmente a disciplina, a disposição para o trabalho e o civismo. Esses valores são mencionados por ex-internos (SANTOS, 2005; SANTOS, 2006) e também destacados nas "notas de impressão" de pessoas que visitaram a instituição, conforme uma das notas extraída do "Livro de Impressões dos Visitantes":

O Aprendizado Agrícola Benjamin Constant é uma organização que infunde confiança nos destinos da mocidade brasileira, dessa mocidade que compreende ser o trabalho o maior fator de dignidade humana e de progresso de um povo. Orientando esse admirável estabelecimento de ensino profissional e cívico, o Dr. José Augusto de Lima tem revelado a lucidez de um espírito perfeitamente cônscio dos magnos problemas da nacionalidade. $\mathrm{Na}$ direção desta casa, ele tem sido, mais do que um 
benfeitor da sua Pátria, um patriarca da juventude que educa, merecendo dos alunos deste Aprendizado, o respeito, e sobretudo a estima a que faz jus pelas virtudes da sua inteligência e a bondade do seu coração.

A ordem, o asseio, o conforto, e mais que tudo isso, a excelente educação que aqui se proporciona aos pequenos brasileiros acolhidos sob a proteção do Governo Federal, evidenciam o valor da grande obra que o Brasil está realizando no setor da assistência social. Severino Pessôa Uchoa (APRENDIZADO AGRíCOLA DE SERGIPE, 1935, p. 12)

As práticas cerimoniais da escola também funcionaram como formas “padronizadas de sociabilidade" (GOFFMAN, 1974), uma interligação entre dirigentesinternos. Foram exemplos os jogos internos e as festas em que ocorria uma suavização dos rigores do internamento e certas liberações dos papéis sociais. Essas liberações ficavam evidentes nos campeonatos internos de futebol em que a "equipe dirigente" e os internos ficavam muito próximos.

As cerimônias ainda exerceram a função de "exibição institucional" do estabelecimento aos visitantes para mostrar que tudo funcionava bem e, ao mesmo tempo, procuravam garantir a manutenção das relações do microcosmo do internato com o macrocosmo social por uma "ligação burocrática e de subordinação". Assim, nas cerimônias cívicas, solenidades de inaugurações, festas, entre outras, o estabelecimento contou com a participação de pessoas externas, muitas vezes autoridades, momento em que a "equipe dirigente" criava uma "imagem calculada e adequada" do estabelecimento (GOFFMAN, 1974). Eram comuns as visitas dos "padrinhos políticos" dos diretores para receberem homenagens ou um reconhecimento político pela indicação à função, como foi o caso do então governador do estado Leandro Maynard Maciel (1955-1959) que, na segunda metade da década de 1950, costumava visitar esse estabelecimento a convite do diretor Wanderley do Prado Barreto: “Dr. Leandro sempre visitou essa escola, porque foi ele que botou Dr. Wanderley lá. Dr. Wanderley sempre que tinha uma festividade chamava ele" (LIMA, 2005). Nas visitas, colocou-se em curso um processo de simbolização no qual as partes melhores e novas eram apresentadas pela "equipe dirigente" garantindo uma visão positiva do estabelecimento. No "Livro de Impressões dos Visitantes" da escola foram anotados registros positivos sobre o estabelecimento, 
mas é preciso realizar uma análise global das fontes disponíveis, pois os visitantes de uma "instituição total”

[...] tendem a ver, naturalmente, apenas os internos mais cooperadores e serviçais, e as partes melhores do estabelecimento [...] Os visitantes podem, facilmente, considerar a lealdade e as habilidades sociais desses recepcionistas como um exemplo do caráter de todo o grupo de internos. (GOFFMAN, 1974, p. 91)

De fato, as "impressões dos visitantes" são fontes ricas, mas como toda fonte, elas tendem a "monumentalizar" o passado, encerrando-o em uma representação interessada que deve ser devassada e analisada em conjunto com as demais fontes disponíveis (LE GOFF, 2003). O almoço servido por ocasião das festividades, das quais comumente pessoas externas participavam, é exemplificativo. Nessas ocasiões, o cardápio sofria uma "melhora" (SANTOS, 2005). Na verdade, a mudança tinha por objetivo exibir a escola de forma positiva aos visitantes e para que a "equipe dirigente" contasse com uma participação "animada" dos internos. Todavia, alguns visitantes poderiam concluir que a refeição servida representava a rotina do cardápio no internato do estabelecimento.

Através das cerimônias cívicas, a instituição procurou cultivar nos internos princípios de moralidade, civilidade e patriotismo. Fez isso principalmente destacando um vulto nacional como exemplo a ser seguido, com os desfiles (internos e externos), solenidades de saudação ao pavilhão nacional, palestras, plantio de árvore, cantos, entre outras. As lições sobre moral e civismo, sobretudo aquelas que exaltavam os valores republicanos, faziam parte de um contexto mais amplo. Já vinham sendo introduzidas nas instituições educativas brasileiras desde as primeiras décadas do século $X X$, representavam uma confiança no papel moralizador da escola e, sobretudo, visava a incutir o nacionalismo na juventude brasileira (HORTA, 1994; SOUZA, 1998). Nesse contexto, as prescrições, no discurso e nas reformas da "Escola Nova", também procuraram incentivar a moralidade pela imitação das virtudes dos grandes "vultos nacionais", objetivando forjar uma juventude nacionalista e patriota de homens que apresentassem características varonis (HORTA, 1994). 
Acompanhando a efervescência das ideias nacionalistas e cívicas dessa época, a Lei Orgânica do Ensino Agrícola dedicou um capítulo à “Instrução Moral e Cívica”, no qual determinava que os estabelecimentos de ensino agrícola deveriam ter um "cuidado especial e constante com a educação moral e cívica de seus alunos”. Essa instrução deveria ser mediante a execução de atividades que englobassem todos os programas, de modo que "todas as atividades e circunstâncias, deverão transcorrer em termos de elevada dignidade e fervor patriótico" (APRENDIZADO AGRÍCOLA BENJAMIN CONSTANT, 1946).

\section{O 18 de outubro: Homenagens ao patrono Benjamin Constant}

As festas em homenagem ao patrono Benjamin Constant eram marcantes para os internos e representaram, além dos valores que a instituição procurou incutir, um momento de quebra da rotina do internato:

A festa mais marcante de lá era no dia dezoito de outubro que se comemorava o dia do patrono Benjamin Constant. Então era uma festona 018 de outubro. Tinha tudo, tinha jogos, tinha voleibol, futebol de campo, um grande almoço. lam convidados de Aracaju, era um dia maravilhoso. O diretor convidava. Tinha desfile, subia e descia tocando as cornetas e tambores. A comida melhorava um pouco. (SANTOS, 2005)

O ponto alto das homenagens ao patrono eram os desfiles cívicos internos anuais, que começavam com a concentração do lado direito do edifício-internato e seguiam percorrendo a estrada defronte ao edifício-internato, retornando para a entoação do hino nacional e o hasteamento dos pavilhões. Na figura a seguir, observa-se aspecto do desfile interno ocorrido em 18 de outubro de 1955. Em destaque, a banda de tambores conduzindo os pelotões em direção ao edifício-internato, sob a supervisão do guarda de alunos. A imagem também mostra a visão do espaço frontal ao edifício-internato (as tradicionais palmeiras imperiais, a estrada antiga, casas de funcionários, casa de farinha, no final, a área de plantio de arroz e, logo depois, o rio Poxim-Assu). 


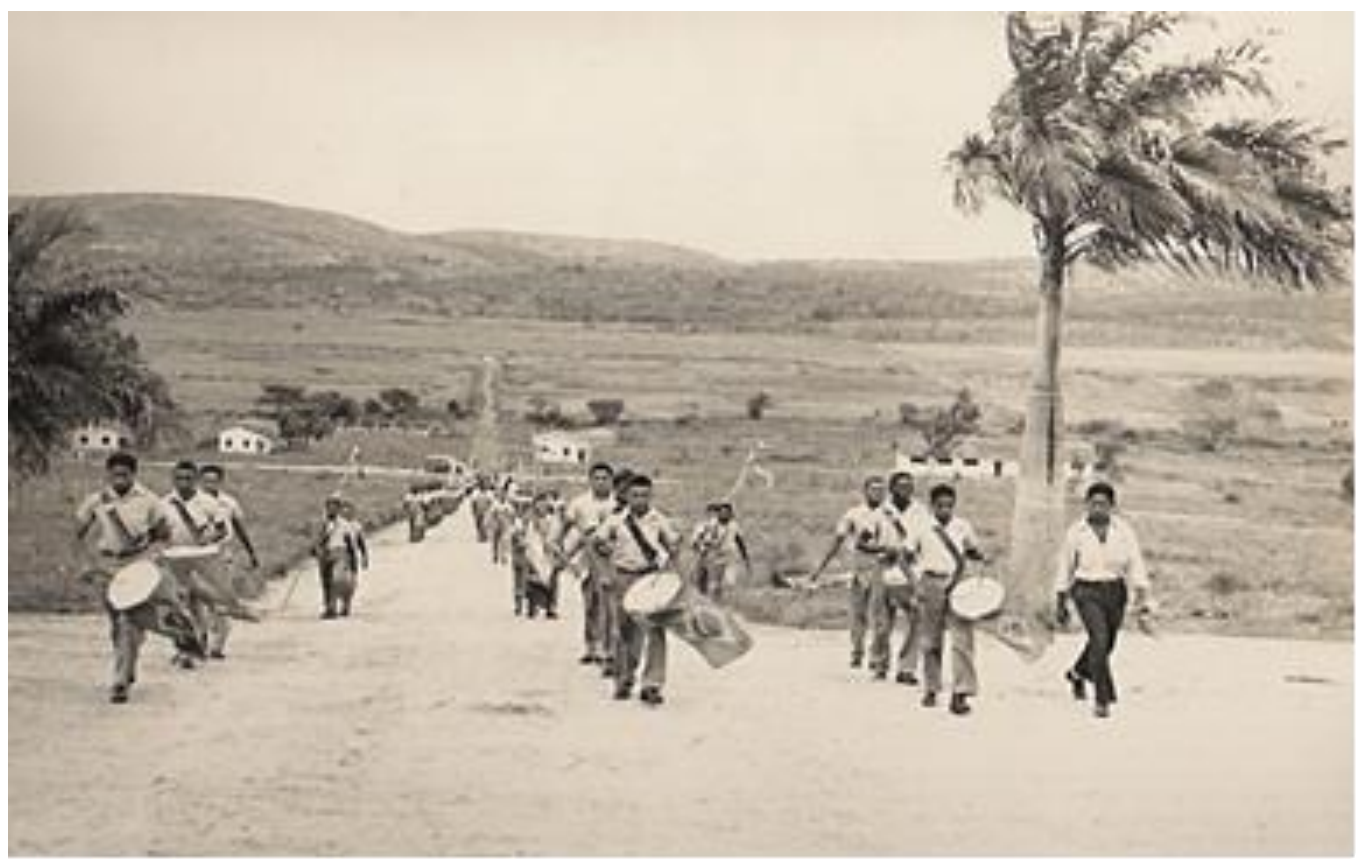

Figura 2. Desfile cívico interno em homenagem ao patrono Benjamin Constant (18/10/1955). Fonte: ESCOLA AGROTÉCNICA BENJAMIN CONSTANT, 1957.

Até meados da década de 1950, o desfile ocorria sob a supervisão do professor de Educação Física, o sargento José de Souza Sobrinho, auxiliado pelo inspetor Antonio Pereira da Silva e os guardas de alunos. O internato formado desfilava em diversos pelotões puxados pela banda de tambores e cornetas. No primeiro pelotão, seguiam os pavilhões nacional, estadual e da escola. Na fase de Aprendizado Agrícola, os internos trajavam uma farda de gala que imitava o fardamento militar da época. Era a camisa, calça e casquete "cáqui" e as botas do tipo reiúnas ou sapatos borzeguins (APRENDIZADO AGRÍCOLA BENJAMIN CONSTANT, 1946; GREGÓRIO, 2005). No decorrer da década de 1950, o fardamento era calça cáqui e a camisa branca ou azul com o escudo da instituição, o cinto e o sapato pretos do tipo borzeguins.

No dia comemorativo, além do desfile cívico, ocorriam cantos cívicos, discursos, palestras, o almoço especial de confraternização e o fechamento com atividades esportivas.

Finalizando o dia de Benjamin Constant, houve duas grandes pugnas esportivas com a escola Industrial de Aracaju, onde em renhida, porém amistosa peleja, nossa equipe saiu vitoriosa das pugnas pebolisticas e cestobolisticas, conquistando as taças Benjamin Constant e Ministério da Agricultura, respectivamente. (ESCOLA AGRíCOLA BENJAMIN CONSTANT, 1955, p. 39) 
Com a criação, no início dos anos 1950, do Centro de Tratoristas, do Curso de Operário Agrícola conveniado com a CBAR (Comissão Brasileiro-Americana de Educação para as Populações Rurais), e dos Centros de Economia Rural Doméstica, agregados à instituição, os alunos e alunas provenientes desses cursos também passaram a formar pelotões específicos no desfile em homenagem ao patrono Benjamin Constant. Durante toda a década de 1950, a cerimônia de homenagem ao patrono se fez de forma contínua e forte. Em 1955, a cerimônia ocorreu de forma grandiosa com destacada participação da comunidade externa:

Merecem especial destaque as comemorações aqui realizadas no dia 18 de outubro, data do nascimento do nosso grande patrono - Benjamin Constant. (...) Contamos com a presença de mais de 600 pessoas, desde as mais altas autoridades estaduais e federais até o mais humilde morador da região. Foi um verdadeiro espetáculo de fé, civismo e patriotismo, onde a mocidade sentiu com fervor o dever de cultuar a memória dos nossos grandes homens. (ESCOLA AGRíCOLA BENJAMIN CONSTANT, 1955, p. 39)

A imagem de Benjamin Constant era incutida através de discursos e palestras cívicas e da leitura da biografia Esboço de uma apreciação sintética da vida e da obra do Fundador da República Brazileira. Trata-se de uma edição comemorativa ao primeiro centenário de nascimento de Benjamin Constant - 18 de outubro de 1936 - de autoria de Raymundo Teixeira de Mendes. Logo na apresentação da edição, é ressaltado o interesse da obra para a mocidade:

Mas é aos moços, dizemos, que ele especialmente serve, pois não pode haver nenhum jovem dotado de civismo que - depois de apreciar a vida ezemplar do Fundador da República - não se ache no dever de contribuir para que o Brazil sáia do sistema habitual de esploração política, e retorne o verdadeiro caminho que convém ao seu gloriozo destino! (RABELLO, 1936)

Provavelmente, desde a década de 1940, o livro faz parte do acervo da Biblioteca da escola e foi consultado por professores e internos. Os empréstimos com maior intensidade ocorriam justamente no mês de outubro, época dos principais atos de homenagens ao patrono Benjamin Constant (COLÉGIO AGRÍCOLA BENJAMIN CONSTANT, 
1956).

Além de reverenciar a imagem do patrono Benjamin Constant, outros vultos nacionais e estaduais eram lembrados, a exemplo do presidente Getúlio Vargas e do intelectual sergipano João Ribeiro, patrono da biblioteca do estabelecimento (ESCOLA AGRÍCOLA BENJAMIN CONSTANT, 1955). No "salão de honra", localizado no edifíciointernato, existia uma galeria de quadros com uma verdadeira pletora de "heróis nacionais" e de autoridades federais e estaduais. Figuravam nesse salão, entre outros, os retratos de Benjamin Constant e do presidente Getúlio Vargas. O espaço é recordado por ex-internos da instituição como o "salão dos retratos", um espaço bonito e que causava uma boa impressão (GREGÓRIO, 2005). No salão da biblioteca ficava o retrato do professor João Ribeiro (APRENDIZADO AGRíCOLA DO SERGIPE, 1939, p. 1).

No decorrer da década de 1960, iniciou-se na instituição um esquecimento do patrono. A imagem de Benjamin Constant foi aos poucos se reduzindo ao nome dado ao estabelecimento e ao retrato na parede. Os desfiles cívicos internos em sua homenagem desapareceram. As cerimônias cívicas já não tomavam a figura do patrono como modelo; agora, o ponto alto eram as comemorações da "Semana da Pátria". Nesse evento, ocorria o desfile interno, reuniões cívico-escolares, discursos, palestras, poesias, representações teatrais, atividades esportivas, entre outras atividades. Ao se aproximar a "Semana da Pátria", os ensaios da banda escolar eram intensificados para a realização do desfile cívico: "Tinha banda de cornetas que saía para a formatura, o ensaio era à tarde. Ela só tinha aquela obrigação quando tava se aproximando o Sete de Setembro" (GREGÓRIO, 2005). No desfile interno eram formados pelotões que saíam marchando pelas estradas defronte ao edifício-internato: "Sete de Setembro quando a escola não desfilava aí fazia uma comemoração, uns discursos de professor e aqueles alunos mais graduados [...] levantava o pavilhão ali em frente ao prédio" (SANTOS, 2005). 


\section{Considerações finais}

Os alunos da EAFS-SC, no período de 1939 a 1960, participaram de um conjunto de práticas periódicas e institucionalizadas, "cerimônias institucionais", que a instituição colocou em prática visando incutir nos internos princípios de moralidade, civilidade e patriotismo. Fez isso principalmente destacando um vulto nacional, Benjamin Constant, como exemplo a ser seguido. As lições sobre moral e civismo introduzidas nas instituições educativas brasileiras representavam uma confiança no papel moralizador da escola e, sobretudo, visava a incutir o nacionalismo na juventude brasileira (HORTA, 1994; SOUZA, 1998).

Através das cerimônias anuais do "18 de outubro" em homenagem a Benjamin Constant, a Instituição apropriou-se da imagem de um "herói nacional”, para através das comemorações incutir o civismo e o patriotismo entre os seus alunos. De fato, as festividades do dia "18 de outubro" foram um instrumento eficaz de instrução cívica como pode ser evidenciado nas memórias de ex-internos. Contudo, uma vez atingidos os objetivos institucionais, os internos igualmente se apropriavam dessas atividades como uma prática suavizante. Era também para eles uma oportunidade para quebra dos rigores da rotina do internato com diversas atividades recreativas e liberalizantes. Assim, ao se apropriarem dos dispositivos e práticas da cultura escolar (JULIA, 2001), os internos selecionavam, reinterpretavam e empreendiam ações múltiplas e de significados diferenciados das práticas postas em circulação na cultura escolar pela "equipe dirigente" (GOFFMAN, 1974).

No percurso do decênio de 1960, ocorreu o arrefecimento da figura de Benjamin Constant na escola. Praticamente esquecido, o patrono foi relegado a um quadro na parede e ao seu nome emprestado ao estabelecimento. São indícios desse declínio a falta de esforço e/ou mobilização simbólica por parte da "equipe dirigente" em torno da promoção da figura do patrono, entre os internos, causando, por conseguinte, a falta de envolvimento desses. Nas memórias coletadas entre estudantes e "equipe dirigente" que fizeram parte da Instituição na década de 1960, fica evidente a diminuição da menção à figura do patrono Benjamin Constant, especialmente quando comparado às memórias de gerações anteriores.

Assim, como não surgiu espontaneamente nem contava mais com a mobilização 
nacional ou "profundidade popular" (CARVALHO, 1990) em torno de sua figura, o patrono da escola, para não cair no esquecimento, precisava continuar sendo lembrado e engrandecido por meio de diversas cerimônias institucionais como havia ocorrido nas décadas precedentes. Todavia, Benjamin Constant, o “fundador da República”, já não servia aos "interesses da ocasião"; outros vultos e práticas visando incutir valores de civismo e patriotismo, provavelmente mais afinados com a doutrina de formação "moral e cívica" do regime implantado no Brasil a partir de 1964, passaram a ser postos em prática na escola.

\section{Referências}

APRENDIZADO AGRÍCOLA BENJAMIN CONSTANT. Livro de anotações de ocorrências do Aprendizado Agrícola Benjamin Constant. São Cristóvão. 1942.

APRENDIZADO AGRÍCOLA BENJAMIN CONSTANT. Livro de correspondência expedida pelo Aprendizado Agrícola Benjamin Constant. São Cristóvão, 1939.

APRENDIZADO AGRÍCOLA BENJAMIN CONSTANT. Livro de registro de entrega de vestuários a educandos. São Cristóvão, 1946.

APRENDIZADO Agrícola de Sergipe. Correio de Aracaju, Aracaju, p. 1, 20 jan. 1939.

APRENDIZADO AGRÍCOLA DE SERGIPE. Livro das impressões dos visitantes. São Cristóvão. 1935 .

BRASIL. Constituição da República dos Estados Unidos do Brasil, de 24 de fevereiro de 1891. SICON (Sistema de Informações do Congresso Nacional), 1891. Disponível em: <<http://www.senado.gov.br/sicon>>

BRASIL. Decreto-Lei n 1.029, de 06 de janeiro de 1939. Dá novas denominações aos Aprendizados Agrícolas do Ministério da Agricultura. SICON (Sistema de Informações do Congresso Nacional), 1939. Disponível em: <http://www.senado.gov.br/sicon>. 
BRASIL. Lei $n^{\circ} 276$, de 17 de outubro de 1936. Declara feriado o dia 18 de outubro de 1936, em comemoração ao centenário do nascimento de Benjamin Constant. SICON (Sistema de Informações do Congresso Nacional), 1936b. Disponível em:

<http://www.senado.gov.br/sicon>.

BRASIL. Decreto n 60.731, de 19 de maio de 1967. Transfere para o Ministério da Educação e Cultura os órgãos de ensino do Ministério da Agricultura e dá outras providências. SICON (Sistema de Informações do Congresso Nacional), 1967. Disponível em: <http://www.senado.gov.br/sicon>.

CARVALHO, José Murilo de. A formação das almas. São Paulo: Companhia das Letras, 1990.

CASTRO, Celso; LEMOS, Renato Luís do Couto Neto (Orgs.). Introdução: uma janela para o tempo. In: MAGALHÃES, Bernardina Botelho de. O diário de Bernardina: da Monarquia à República pela filha de Benjamin Constant. Rio de Janeiro: Jorge Zahar, 2009.

COLÉGIO AGRÍCOLA BENJAMIN CONSTANT. Cartão de controle de retirada de livros da Biblioteca João Ribeiro, São Cristóvão, 1956.

CONCEIÇÃO, Joaquim Tavares da. A pedagogia de internar: história do internato no Ensino Agrícola Federal (1934-1967). São Cristóvão: Editora UFS, 2012.

ESCOLA AGRÍCOLA BENJAMIN CONSTANT. Relatório anual de atividades 1955. Wanderley do Prado Barreto, 1955.

ESCOLA AGRÍCOLA BENJAMIN CONSTANT. Relatório anual de atividades 1956. São Cristóvão, 1956.

ESCOLA AGROTÉCNICA BENJAMIN CONSTANT. Relatório anual de atividades 1957. São Cristóvão, 1957.

GREGORIO, José. 2005. Entrevista concedida ao autor no dia 16 de novembro de 2005.

GOFFMAN, Erving. Manicômios, prisões e conventos. São Paulo: Perspectiva, 1974.

HORTA, José Silveiro Baía. O Hino, o sermão e a ordem do dia. Regime autoritário e a educação no Brasil (1930-1945). Rio de Janeiro: Editora UFRJ, 1994.

JULIA, Dominique. A cultura escolar como objeto histórico. Tradução de Gizele de Souza. Revista Brasileira de História da Educação. Campina: Autores Associados, n. 1, p. 09-43, 2001.

LE GOFF, Jacques. História e memória. Campinas: Editora da UNICAMP, 2003. 
LEMOS, Renato Luís do Couto Neto e. "Benjamin Constant: Biografia e Explicação Histórica”. Estudos Históricos, n.19, Rio de Janeiro, 1997.

LIMA, João Ferreira. 2005. Entrevista concedida ao autor no dia 17 de novembro de 2005. MENDES, Raymundo Teixeira. Benjamin Constant. Esboço de uma apreciação sintética da vida e obra do Fundador da República. Rio de Janeiro: Imprensa Nacional, 1936.

NASCIMENTO, Jorge Carvalho do. Memórias do aprendizado: oitenta anos de ensino agrícola. Maceió: Edições Catavento, 2004.

NERY, Marco Arlindo Amorim Melo. A regeneração da infância pobre sergipana no início do Século XX: o Patronato Agrícola de Sergipe e suas práticas educativas. 2006, $153 \mathrm{ff}$. Dissertação (Mestrado em Educação) - Universidade Federal de Sergipe, Núcleo de PósGraduação em Educação da São Cristóvão, 2006.

RABELLO, Manoel. Apresentação. In: MENDES, Raymundo Teixeira. Benjamin Constant: esboço de uma apreciação sintética da vida e obra do Fundador da República. Rio de Janeiro: Imprensa Nacional, 1936.

SANTOS, Reginaldo José dos Santos. 2005. Entrevista concedida ao autor em 18 de novembro de 2005.

SOUZA, Rosa Fátima de. Templos de civilização: a implantação da escola primária graduada no estado de São Paulo (1890-1910). São Paulo: Ed. Unesp, 1998.

SANTOS, Ademilson Vieira. 2006. Entrevista concedida ao autor em 13 de setembro de 2006.

Universidade do Estado de Santa Catarina - UDESC

Programa de Pós-Graduação em Educação - PPGE

Revista Linhas

Volume 17 - Número 34 - Ano 2016 revistalinhas@gmail.com 